\title{
Desvelando o significado da avaliação no ensino por competência para enfermeiros educadores
}

\author{
Revealing the meaning of assessment in competence-based education for nurse-educators
}

Comprendiendo el significado de la evaluación en la enseñanza por competencia para enfermeros educadores

Rosane Aparecida do Prado ${ }^{1}$, Marta Lenise do Prado², Kenya Schimdt Reibnitz ${ }^{3}$

\section{RESUMO}

Trata-se de uma pesquisa participativa, do tipo descritivo-exploratória, de natureza qualitativa, que foi desenvolvida com um grupo de educadores de um Curso Técnico de Enfermagem e teve como objetivos compreender o significado da avaliação da aprendizagem no ensino baseado em competências, estabelecer um processo reflexivo assim como reconhecer crenças e valores da prática avaliativa. O referencial teórico-metodológico baseou-se nos pressupostos de Paulo Freire em sintonia com fundamentos do ensino por competência de Philippe Perrenoud. Para coleta de dados foram utilizadas as técnicas de entrevista e círculos de diálogo, sendo o processo de análise realizado concomitantemente à coleta de dados. Foram trabalhados cinco temas geradores cujos resultados apontam os significados da avaliação como aliança da competência técnica à afetividade e como espaço de diálogo e respeito, revelando a importância da ação pedagógico-avaliativa por meio da reflexão/ação que se associa à avaliação do próprio trabalho pedagógico e à educação permanente dos profissionais.

Descritores: Avaliação educacional; Educação Baseada em Competências; Educação em enfermagem.

\section{ABSTRACT}

This is a participatory, descriptive and exploratory study, using a qualitative approach. It was developed with a group of educators of a Technical Nursing Course with the objectives of understanding the meaning of learning assessment in competency-based education, establishing a reflexive process, and recognizing the beliefs and values regarding the practice of assessment. The theoretical methodological framework was based on the premises of Paulo Freire in line with the foundations of Philippe Perrenoud's competency-based education. Data collection was performed through interviews and discussion groups. The analysis was performed simultaneously with the data collection. Five generating themes were used, whose results point to the meanings of assessment as an alliance between technical competency and affectivity, as a space for dialogue and respect, and reveal the importance of educational/assessment interventions associating the evaluation of the educational work itself and the permanent education of the professionals.

Descriptors: Educational assessment; Education based on Competence; Nursing education.

\section{RESUMEN}

Investigación participativa, de tipo descriptivo exploratorio, naturaleza cualitativa. Desarrollada con grupo de educadores de Curso Técnico de Enfermería, objetivó comprender el significado de la evaluación del aprendizaje en la enseñanza basada en competencias, establecer un proceso reflexivo y reconocer creencias y valores de la práctica evaluatoria. El referencial teórico-metodológico se basó en los supuestos de Paulo Freire, en sintonía con fundamentos de enseñanza por competencia de Philippe Perrenoud. Para recolección de datos se utilizaron las técnicas de entrevista y círculos de diálogo, realizándose el proceso de análisis en forma concomitante. Se trabajaron cinco temas generadores cuyos resultados determinan los significados de la evaluación como alianza de la competencia técnica a la afectividad, como espacio de diálogo y respeto, y explica la importancia de la acción pedagógica/evaluatoria mediante reflexión/acción asociando la evaluación del propio trabajo pedagógico y la capacitación continua de los profesionales.

Descriptores: Evaluación educacional; Educación Basada en Competencias; Educación en enfermería.

\footnotetext{
${ }^{1}$ Enfermeira, Mestre em Enfermagem, Professora, Instituto Federal de Educação Ciência e Tecnologia de Santa Catarina. Florianópolis, SC, Brasil. E-mail: rosane@ifsc.edu.br.

${ }^{2}$ Enfermeira. Doutora em Enfermagem, Professora Associada, Universidade Federal de Santa Catarina (UFSC). Florianópolis, SC, Brasil. E-mail: mpradop@ccs.ufsc.br.

${ }^{3}$ Enfermeira. Doutora em Enfermagem, Professora Titular, UFSC. Florianópolis, SC, Brasil. E-mail: kenya@ccs.ufsc.br.
} 


\section{INTRODUÇÃO}

A avaliação da aprendizagem no ensino por competência compreende um processo de avaliação que se considera ao longo da vida acadêmica do educando e que se sobreponham os aspectos qualitativos sobre os quantitativos, não supervalorizando somente resultados como em provas finais ${ }^{(1)}$.

Ao se falar no modelo de ensino por competências para formação do técnico de enfermagem busca-se problematizar, integrando os saberes em todas as suas dimensões. Esse modelo traz um novo enfoque ao valorizar o saber tácito e a subjetividade do trabalhador ${ }^{(2)}$.

O processo ensino-aprendizagem na enfermagem é um dos desafios na formação de profissionais competentes e compromissados com a saúde e a vida, onde a avaliação da aprendizagem insere-se neste processo de formação, buscando a articulação da teoria com a prática.

O ensino tradicional estava centrado no professor, definindo o que o estudante deveria aprender conforme os conteúdos das aulas, sob uma perspectiva inovadora o estudante passa a ser o foco central, visando formar um profissional com iniciativa e atitude responsável pelo seu aprendizado, com habilidade para a busca de informações e crivo crítico ${ }^{(3)}$.

A discussão acerca da avaliação da aprendizagem implica em falar de mudanças e transformações de métodos tradicionais onde a mesma, muitas vezes, é seletiva, excludente e realizada como forma de soberania sobre os educandos.

Concepções tradicionais de educação revelam a avaliação da aprendizagem como ato de medir ou quantificar em notas o desempenho do ser humano, promovendo a competição, revelando assim a proximidade com a avaliação mais comprometida com a seleção do que o compromisso com a aprendizagem e a formação. Ainda que importante e imprescindivel no planejamento educacional, a avaliação é vista somente como instrumento de seleção e de atribuição de nota ou conceito $^{(4-5)}$.

Em um contexto de mudança do modelo pedagógico, o educador precisa refletir sobre o modo de avaliar a aprendizagem, inserindo-se de maneira crítica e consciente do seu fazer educação.

Avaliar a aprendizagem baseado em competência requer a consideração, não só dos conhecimentos adquiridos, mas também das habilidades e das atitudes desenvolvidas pelos educandos e as esperadas no conjunto da proposta pedagógica. Visa o crescimento do aluno tomando como referência as competências profissionais a serem adquiridas, não se restringindo ao resultado do desempenho, porém, a partir deste, projetar estratégias que favorecerão o desenvolvimento das competências necessárias ao trabalho(6).

Para tanto, ela precisa ser considerada uma atividade inerente a aprendizagem e a proposta pedagógica, necessita ser contínua e sistematizada para ser reconhecida como uma das atividades educacionais mais expressivas do ponto de vista da mobilização dos educandos ${ }^{(7)}$.

Competência é a capacidade de agir eficazmente em um determinado tipo de situação, apoiada em conhecimentos, mas sem limitar-se a eles. Para enfrentar uma situação da melhor maneira possível, deve-se, via de regra, pôr em ação sinergicamente vários recursos cognitivos complementares que promovam a mobilização de saberes, capacidades e informações, entre os quais estão os conhecimentos ${ }^{(8)}$.

Na abordagem dialógica de competência há também uma mudança no papel da escola e dos docentes na relação com estudantes e com o mundo do trabalho. Essa mudança ancora-se na constatação da existência de diferentes saberes onde não deve ocorrer subordinação e sim, complementariedade na integração teoriaprática ${ }^{(7)}$.

O ensino por competência precisa provocar o diálogo entre os conhecimentos disciplinares e a experiência do trabalho, potencializando as mudanças no processo formativo de maneira crítica e emancipadora, trazendo em seu bojo os princípios fundamentais de e para uma educação profissional ampliada(9).

A educação profissional no Brasil, mediante a Lei de Diretrizes e Bases da Educação Nacional - LDB(1), propõe a implementação de propostas pedagógicas apoiadas no modelo de ensino por competências. Desta maneira, em muitas Escolas de Ensino Profissionalizante de Enfermagem no Brasil foi desencadeado um processo de reestruturação curricular, fundamentalmente no tocante aos modelos pedagógicos por competência, aí incluídos os processos avaliativos dos alunos. Contudo essas mudanças para se consolidarem precisam de tempo, necessitam passar por uma revolução cultural envolvendo toda a Escola e a sociedade ${ }^{(8)}$. 
Mediante tais constatações percebe-se a necessidade de reflexão e compreensão acerca do processo da avaliação da aprendizagem no ensino por competência.

Frente a este cenário, esta pesquisa teve por objetivos, compreender o significado da avaliação no ensino por competência para educadores de um Curso Técnico de Enfermagem, bem como estabelecer um processo reflexivo e reconhecer crenças e valores da prática avaliativa.

\section{MÉTODO}

Trata-se de um estudo de natureza qualitativa, participativo e baseado no itinerário teóricometodológico de Freire ${ }^{(10)}$, os círculos de cultura, que compreende: levantamento dos temas geradores (1 ${ }^{a}$. fase da investigação), codificação e decodificação ( $2^{a}$. fase) e desvelamento crítico ( $3^{a}$. fase). Optou-se por este referencial para atingir os objetivos propostos pois o mesmo se baseia no diálogo, na formação de temas geradores emergidos a partir da necessidade dos grupos, em que se busca a codificação e decodificação para um desvelamento crítico, por meio da transformação da realidade. Desse modo, os integrantes dos círculos de cultura são conduzidos de forma processual e contínua, a refletir sobre as suas realidades, oportunizando o relato de suas experiências, sentimentos, percepções e expectativas $^{(10)}$. Nesse estudo, os círculos de cultura são denominados de círculos de diálogo.

O estudo foi realizado no período de agosto a outubro de 2006 em uma instituição educacional de autarquia federal, localizada no sul do Brasil, que oferece, entre outros cursos na área da Saúde, o Curso Técnico de Enfermagem. Este Curso tem seu Plano Politico Pedagógico fundamentado no ensino por competência desde 2002 e seu corpo docente vem enfrentando os desafios inerentes ao processo de implantação de um novo currículo desde então.

Participaram do estudo seis enfermeiros educadores desse Curso, que desenvolvem com os alunos os módulos teórico-práticos. A decisão em trabalhar com os educadores do Curso Técnico de Enfermagem, como sujeitos do processo de avaliação, aconteceu por acreditar-se que re-significando este tema multifacetado, dar-se-ia um novo sentido à avaliação da aprendizagem por quem a imprime, como também um novo sentido à questão metodológica. Os critérios de inclusão foram: ter disponibilidade e aceitar participar do estudo.

Para o levantamento dos temas geradores ( $1^{\text {a }}$. etapa da fase de investigação), foram realizadas entrevistas semiestruturadas com cada um dos participantes. As questões norteadoras da entrevista foram: Qual o significado da avaliação da aprendizagem no ensino por competência para você? Como você vê a avaliação da aprendizagem no ensino por competência? Como é sua prática avaliativa, hoje, no ensino por competência? A partir da sistematização das entrevistas foram identificados os temas geradores, os quais posteriormente foram apresentados e referendados pelos docentes no grupo de diálogo. Os temas geradores identificados foram: (1) a avaliação da aprendizagem no ensino por competência é difícil; (2) a avaliação da aprendizagem é subjetiva; (3) os educadores têm pouco conhecimento sobre o ensino e a avaliação por competência; (4) há necessidade de os educadores falarem a mesma linguagem na prática avaliativa e (5) o ensino ainda está muito tradicional, apesar de ser chamado por competência.

No segundo momento da coleta de dados, foram realizados os encontros grupais - círculos de diálogo, análogo ao círculo de cultura de Freire(11). Cada um dos círculos de diálogo foi organizado com base nos temas geradores, num total de cinco, teve uma duração média de 1 h30min e foi desenvolvido a partir de uma dinâmica de aquecimento, seguido pelas discussões propriamente ditas (codificação e decodificação) e por uma avaliação do encontro pelos próprios participantes. As etapas de codificação e decodificação foram realizados em quatro círculos de diálogo e o desvelamento crítico no quinto e último encontro, o qual foi realizado cinco meses após o último encontro de codificação e decodificação. Esse tempo foi necessário para que os sujeitos pudessem refletir sobre suas práticas e sensibilizar-se para a transformação respondendo às mudanças de forma ativa e eficaz.

O processo de análise dos dados foi concomitante com a coleta dos dados e realizada nos círculos de diálogo, de acordo com os pressupostos do itinerário teórico-metodológico de Freire. Os temas geradores foram discutidos/explorados em cada encontro do círculo de diálogo e à medida que o diálogo se dava, a codificação, a decodificação e o desvelamento crítico ocorriam de modo coletivo. A discussão realizada no 
encontro servia de subsídio para o encontro seguinte e, assim, sucessivamente. As falas foram gravadas e transcritas, submetidas a uma pré-análise e posteriormente apresentadas no encontro seguinte para os participantes do círculo de diálogo.

O estudo foi submetido ao Comitê de Ética e Pesquisa com Seres Humanos da Universidade do Sul de Santa Catarina e aprovado sob o parecer de $n^{\circ}$ 06.173.4.04.III. No primeiro encontro foi entregue o Termo de Consentimento Livre e Esclarecido aos participantes, informando-os acerca da garantia do anonimato, da liberdade de participação e de desistência, se assim o desejassem.

\section{RESULTADOS E DISCUSSÃO}

A partir do levantamento dos temas geradores foi desencadeado o processo de codificação, decodificação e desvelamento crítico, nos círculos de diálogo, de acordo com o itinerário teórico-metodológico de Freire.

Os temas geradores são compreendidos como temas vividos pelos indivíduos relacionados com o dia-a-dia dos sujeitos e do grupo social a que pertencem e surgem da realidade concreta dos sujeitos. A codificação consiste na fase de apreensão do conjunto de contradições presentes nesses temas geradores. É a fase de tomada de consciência, transformando a sua primeira visão ingênua em uma visão crítica do assunto.

A decodificação é a fase em que os sujeitos refazem suas reflexões sobre o vivido para analisarem criticamente seus contextos, problematizando e, ao mesmo tempo, distanciando-se da realidade, a fim de se reconhecerem como seres transformadores. É o momento em que os indivíduos passam a transformar a realidade e sua consciência de mundo.

Esse processo está sendo apresentado e analisado a partir dos temas geradores.

\section{Tema Gerador I - A avaliação da aprendizagem no ensino por competência é difícil}

As práticas de ensino e aprendizagem não mudam só porque a legislação de ensino mudou, pois para que esse processo se concretize se faz necessário passar por uma mudança de cultura, tanto com os professores quanto com os alunos e comunidade em seu entorno(8).

Os sujeitos da pesquisa expressaram a dificuldade de realizar a avaliação por competência, pois consideraram o ensino por competência uma modalidade diferenciada. Para eles a reforma da educação, segundo a Lei de Diretrizes e Bases 9.394/1996, implica em reformular velhos conceitos, inclusive acerca da avaliação e que, talvez por isso, gere tantas interpretações diferentes.

Os educadores atribuem a dificuldade da avaliação por competência à falta de preparo das escolas, ao MEC que instituiu uma política sem discuti-la com os envolvidos, aos próprios alunos que tem necessidade de receber uma nota, aos conflitos que o próprio educador vive e a dificuldade em apreender os aspectos subjetivos da avaliação. Conforme podemos identificar nos depoimentos a seguir.

[...] Acho que a dificuldade da avaliação por competência é que nem todas as escolas estão adequadas a essa nova metodologia, sendo culpa do MEC que poderia usar de estratégias de multiplicação na implantação do ensino por competência (Azaléia).

[...] O aluno necessita de um "score" para sua avaliação, ele quer saber do número, quanto ele tirou. E o professor entra em conflito com isso (...) (Begônia).

Os educadores constataram que a avaliação já foi exercida por eles como forma de poder. Reconhecem que o saber gera o poder; porém, nesse contexto, aparece a "consciência crítica"(11) de que nos tempos atuais o educador deixou de ser o mestre o único possuidor de conhecimento, já que os educandos trazem também um saber, originado em seu mundo, em sua realidade e desejam socializar tais conhecimentos, numa relação de ensinar e aprender.

[...]Muitas vezes o professor é injusto por colocar suas verdades como prioridade ao fazer a avaliação. Precisamos ter um individuo com habilidades, com ética e partícipe no palco da vida, pois o professor acha que ainda tem o poder sobre os alunos, e hoje esses alunos têm muito conhecimento e querem ter voz e vez (Cravo).

Avaliar a aprendizagem é avaliar o ensino oferecido, mas também é avaliar o modo de aprender, e para tanto se faz necessário que este processo seja contínuo e que ajude no desenvolvimento da competência ${ }^{(12)}$.

O que identificamos é que também para os educadores, sujeitos da pesquisa, a dificuldade na avaliação da aprendizagem ocorre pelo pouco 
conhecimento acerca do processo de avaliação e do ensino por competência. Então, se faz necessário aprofundar conhecimento por meio de reflexões, discussões, a fim de obter-se um embasamento sustentável para a realização de uma prática avaliativa adequada. Os educadores têm necessidade de expressar suas angústias e também de relatar suas experiências vividas no espaço pedagógico do ensino profissionalizante.

As diretrizes gerais para a educação dos profissionais de saúde do século XXI descrevem que o desenvolvimento de competências deve estar dirigido à busca da integralidade da atenção à saúde, contribuindo para a formação de um profissional que agregue aptidões para tomada de decisões, comunicação, liderança, gerenciamento e educação permanente ${ }^{(13)}$.

\section{Tema Gerador II - A avaliação da aprendizagem é subjetiva e Tema gerador III - Há pouco conhecimento acerca da avaliação por competência.}

Nessa concepção pedagógica, a educação se desenvolve a partir do humano, isto é, mobiliza sujeitos que trazem como elementos constitutivos do seu ser uma história de vida, uma origem sociocultural, saberes constituídos ao longo da sua formação e vivências no trabalho em saúde, isto é, toda a complexidade do viver que forma uma certa subjetividade e coloca em ação no mundo uma forma singular ${ }^{(14)}$.

No processo avaliativo, portanto, se faz necessário avaliar não apenas o conhecimento e as habilidades, mas também, as atitudes do aluno no processo de aprendizagem, aí incluída relação educador-educando, educando-educando, educando-profissionais, educandocliente. A avaliação não é um processo punitivo e unidirecional, mas uma oportunidade de rever o modo como cada um vem se colocando frente as situações de aprendizagem, deve ser vista como mais uma estratégia de aprendizagem ${ }^{(15)}$.

Estes educadores acreditam que a subjetividade é inerente à prática avaliativa, mas é ao mesmo tempo o que mais dificulta o processo. Isso é decorrente do reconhecimento de que a avaliação não é simplesmente uma prática de mensuração. E, o que já era subjetivo - aí especialmente a avaliação teórico-prática na formação em Enfermagem - hoje, com a proposta de avaliar habilidades, atitudes e conhecimentos, passa a ter um caráter ainda mais subjetivo, pois envolve a complexidade das relações entre o saber e sua relação e aplicação na prática. Não é o resultado de uma única estratégia avaliativa que diagnosticará o processo, mas uma diversidade ao longo da trajetória escolar.

\section{[...] A prova é apenas um método de tantos outros para se} pontuar na avaliação. É preciso olhar o aluno como um todo e perceber o crescimento dele. E não é fácil. Para diminuir essa subjetividade temos que descrever a atuação do aluno diariamente. Existe uma construção do conhecimento realizado por ele e não se pode ter uma visão estreita: só aquela prova que o aluno fez, por exemplo. O resultado da prova não deve ser pontual; é apenas um recurso. Penso que é aí que estamos deixando a desejar, é o que está faltando. o professor precisa descrever os outros aspectos que complementam a avaliação como um todo[...] (Girassol).

Рага isso, os educadores acreditam que eles próprios devem estar cientes dos critérios da avaliação por competência e serem capazes de esclarecê-los aos educandos. Esse processo dialógico, passou a despertar a tomada de consciência e a mesma está se fazendo presente, seja contextualizando suas práticas, seja questionando ações até então estabelecidas.

[...]Deveria ser normatizado alguns parâmetros para descrever esta subjetividade. Talvez seja uma das razões da insegurança do professor, não conseguir pontuar essa subjetividade. Porém deveria haver diálogo entre professor e aluno, deixando claro que até aquela aula que o professor ministrou é fator de avaliação e não só repasse da informação. No entanto nem sempre o próprio professor percebe esse momento como de avaliação [...](Begônia).

Os professores necessitam compreender que a subjetividade da prática avaliativa estará sempre presente, mas a partir da relação dialógica entre os envolvidos que dela participam e a utilização de uma linguagem compreensiva e acolhedora, a obtenção de consenso poderá ocorrer ${ }^{(2)}$.

Quando os educadores refletem acerca do pouco conhecimento sobre a avaliação, justificam este fato por serem Enfermeiros e não pedagogos, ou seja, pela falta de formação pedagógica. Nesse momento, aparece nas entrelinhas a "consciência ingênua"(11). Inter-relacionam 
a subjetividade e o pouco conhecimento devido ao fato de a cultura pedagógica ter sua raiz no ensino tradicional, na forma de avaliação classificatória e excludente. Por isso, para que ocorra a mudança deve haver abertura para ideias novas, e para isso é preciso uma ação intencional, que necessita de conhecimentos e oportunidades para reflexões e discussões. Para tanto, o principal recurso do professor é a sua prática reflexiva, sua capacidade de observar, de inovar e de aprender com os outros ${ }^{(8)}$.

\section{[...]Avaliar pressupõe que o professor esteja preparado $e$} seja competente para avaliar por competência [...](Begônia).

A prática reflexiva é uma fonte de aprendizagem, e esta reforça-se com projetos coletivos na escola onde há cooperação grupal e formação em comum. Onde a formação seria pensada numa competência técnica e política ${ }^{(8)}$.

A necessidade de preparo do professor se dá pelo reconhecimento de que o processo de avaliação precisa ser pensado, planejado e realizado de forma integrada e coerente com todo processo de ensino-aprendizagem. $\mathrm{O}$ enfermeiro educador necessita de um maior investimento em sua formação inicial e continuada, munindo-se de competências, estratégias e ferramentas para a condução de um trabalho mais integrado entre seus saberes científicos e pedagógicos(16).

\section{Tema Gerador IV - Há necessidade dos educadores falarem a mesma linguagem na prática avaliativa, com coesão e união.}

Os educadores expressaram a dificuldade do ensino por competência por não se ter a mesma linguagem clara no processo de avaliação. Enquanto alguns se esforçam para transformar a avaliação excludente em dialógica, outros permanecem somente com as provas pontuais, trabalhos em grupo, sem esclarecimento dos reais objetivos dos mesmos, vendo a avaliação somente como resultado final do processo pedagógico.

\section{[...]Eu acho que falar a mesma linguagem também é adotar} instrumentos simples e de fácil manuseio, que contemple o esperado e que os educandos tenham acesso. Porque acho que o grande erro é esse material ser somente do professor como avaliador. E aí seguir o instrumento. Para não se diferenciar muito e falar a mesma linguagem. Isso seria para mim um consenso[...] (Azaléia).

Todavia, eles consideram que todo avaliador imprime sua individualidade e compreensão, sendo impossível uniformizar pensamentos. Distinguem dois momentos diferenciados da vida do educando: o momento da teoria, em seu ambiente de sala de aula, sentindo-se seguros, confortáveis com o que the é familiar e quando vão para estágio supervisionado, em local desconhecido, gerando-lhes insegurança e medo. A questão então é: de que forma uniformizar documentos/instrumentos avaliativos se os contextos e os sujeitos são diferentes?

A concepção de falar a mesma linguagem remete à compreensão de que essa linguagem consiste na mesma atitude de amorosidade, acolhendo o educando para falar a sua linguagem e só a partir de então dialogar com outros profissionais. Isso ocorre porque o educador é aquele que, assumindo o seu estado de adulto, acolhe, nutre, sustenta e confronta seus educandos, estejam no estado em que estiverem. Importa lembrar que tanto o educando quanto o educador são seres em crescimento. Daí podemos, como educadores, assumir nossas condutas adequadas e inadequadas, buscando sempre novas possibilidades ${ }^{(17)}$.

Parece haver unanimidade ao reconhecer que falar a mesma linguagem também é avaliar/olhar o educando sob todos os ângulos. Porque seu contexto vivencial não é só escola. Muitas vezes ele é o pai/mãe de família, o trabalhador que tem problemas pessoais a serem superados. E esse olhar diferenciado deveria ser de tolerância, de reinvestimento, de resgate.

[...] É preciso considerar a realidade do aluno porque ele não é só escola, ele tem vida própria, seus problemas, suas dificuldades pessoais. Por isso a importância em considerar o todo do aluno, tendo paciência em observar, acompanhar, recuperar para então avaliar [...] (Bromélia).

Os participantes do círculo manifestaram desejo de encontrar outros modos de fazer a avaliação. Neste momento, parecem estar "tirando o véu, para ser mais", tentando uma transformação, isso porque a educação para a libertação deve desembocar na prática 
transformadora, ato do educando, como sujeito, organizado coletivamente ${ }^{(11)}$.

Tema Gerador V - 0 ensino ainda está muito tradicional apesar de ser chamado por competência.

Esse tema gerador levou a reflexão sobre a resistência às mudanças e as possibilidades do trabalho em grupo. As falas relataram a dificuldade em realizar mudanças, pois essas causam conflito com o desconhecido, gerando insegurança. Na prática tradicional não se precisa correr risco de exposição, de enfrentar pessoas e situações inovadoras, pois é um caminho conhecido.

\section{[...] Sempre procuramos um caminho que alguém já tenha} feito porque assim não teremos surpresas, não nos expomos, não corremos risco de errar. Além de dar mais trabalho se eu fizer o novo, tenho que enfrentar as pessoas, enfrentar as situações para inovar. É difícil você querer mudar algo que já está cristalizado na cabeça das pessoas[...] (Girassol).

Nada mais confortável e tranquilizador do que dividir o programa escolar em unidades, de preferência independente umas das outras, de maneira que, para cada uma delas, se possa prever um tempo delimitado de sensibilização, de explicação, de exercício e de controle. Todavia, não se pode responsabilizar somente a avaliação tradicional por este modo de transposição didática, mas o fato de dar notas ou conceitos apoiado em uma avaliação padrão reforça-a terrivelmente. Efetivamente o que há de mais simples do que seguir o planejamento, administrar uma prova, dar uma nota e seguir em frente ${ }^{(8)}$ ? Nesse sentido, os educadores também expressaram preocupação com a avaliação por competência, como vemos na fala seguinte:

[...]Avaliação por competência deve ser bem mais abrangente. Porque trabalho em outra escola que deveria se avaliar por conceitos, porém nem sempre acontece... trabalham com notas numéricas, apesar da escola pregar que a avaliação deve ser processual e ao longo de toda a trajetória do aluno e não somente um resultado. E aí vem o aluno e te cobra uma nota porque o outro professor já fez várias provas e eu não fiz nenhuma. Porque tenho outras formas de avaliação além da prova. Mas dá um nó na cabeça do aluno, porque o correto passa a ser o outro e não você [...](Bromélia).

Nesse contexto, se a escola der tanto peso à aquisição de conhecimentos descontextualizados e tão pouco à construção de competências, toda a avaliação correrá o risco de se transformar em um concurso de excelência ${ }^{(8)}$.

As expressões dos educadores demonstraram a compreensão de que as práticas educativas e avaliativas ainda são tradicionais, embora reconheçam que a mudança embora difícil, seja necessária. Um processo de mudança requer coragem e ousadia e, muito frequentemente, não estamos dispostos a correr riscos. Nesse sentido, são necessários espaços de discussão e reflexão, que favoreçam o processo de transformação, necessário para desenvolvermos ensino por competência. Quando se tem segurança do que se vai fazer, tem-se mais coragem de correr riscos.

Рага o desenvolvimento de práticas pedagógicas inovadoras, os educadores precisam planejar situações didáticas e atividades que traduzam sentido para os alunos, envolvendo-os, e, ao mesmo tempo, gerando aprendizagens fundamentais ${ }^{(8)}$.

O desvelamento crítico é o momento em que a consciência do problema existencial compartilhado agora é revisto, possibilitando uma nova ação na busca de superação e não mais de adaptação. Problematizar as situações vividas é refletir sobre elas. Com essas reflexões, começam a aparecer os códigos das situações e, consequentemente, decodificações surgirão, pois à medida que as discussões se expandem, outros olhares emergem. E, para mudar a realidade vivida, acontece o que Freire chamou de "Desvelamento Crítico", o qual representa a tomada de consciência da realidade vivida, possibilitando uma ação na busca da superação e não mais de adaptação(11).

Os educadores reprovaram a forma tradicional e bancária de educação e idealizaram uma educação mais democrática e ética. Mostraram aversão a um formato de educação perverso e, ao mesmo tempo, afirmaram ter dúvidas se nos dias atuais se tenha mudado o ver e o fazer do processo pedagógico.

[...]Infelizmente ainda hoje existem formas de coerção, tem alguns professores que talvez não batam com a régua (...), mas a partir do momento que o professor despreza o 
comentário do aluno, que se torna sarcástico, se torna agressivo, a falta de consideração com o aluno é a mesma. Falta o respeito [...](Azaléia).

Numa relação pedagógica democrática, o professor precisa ter respeito pelo educando, usando de empatia para colocar-se em seu lugar. A educação democrática e crítica possibilita uma educação participativa para promover a liberdade e autonomia, visa construir um ambiente educacional e profissional menos distorcido por relações de poder ${ }^{(17)}$.

[...]O aluno tem que ter oportunidade de expressão nesta nova metodologia por competência, o que antes não se visualizava; era nota pela nota, era só o conhecimento. Hoje se tenta fazer de outra forma dando rosto e deixando a expressão acontecer[...] (Girassol).

O ensino por competência propõe uma união entre o conhecimento prévio dos educandos e a construção do saber mediado pelo educador, levando o educando a construir seus significados de aprendizagem conforme sua realidade. O modelo por competências valoriza a postura ativa do aprendiz no processo, por considerá-lo ator do aprendizado tanto quanto aquele que ensina(5).

Os educadores manifestaram necessidade de transformar suas realidades pedagógicas, aprimorar suas avaliações e conhecer profundamente os aspectos que envolvem o processo educativo/avaliativo, levando a um desvelamento crítico e a uma tomada de consciência. "O despertar para a consciência de uma prática mais crítica e reflexiva deve começar a ser encorajada desde o processo de formação dos profissionais técnicos de enfermagem"(18).

A partir dos encontros de Círculo de Diálogo, os educadores demonstraram uma forma mais flexível na concepção do processo avaliativo, quando antes era visto como resultado e, agora, percebido como acompanhamento do crescimento do aluno. Assim, eles compreenderam que a avaliação não é um momento pontual, estagnado, mas que permeia todo o processo pedagógico, devendo ser contextualizada com o todo.

[...] Eu hoje acho que a avaliação faz parte de toda atividade e antes eu a via como um resultado final, ou seja, vejo que a avaliação deve ser contextualizada junto à atividade educativa e antes via como uma atividade a parte. Hoje eu me preocupo mais em contribuir com o aluno no principio educativo e avaliativo que é tudo junto. E mediante as discussões de sala de aula há uma construção da própria avaliação[...] (Azaléia).

Após o processo vivido pelos educadores participantes do estudo, algumas mudanças foram percebidas. Dentre outras, foi mudado o instrumento de avaliação da aprendizagem com orientações a todos, de maneira a tornar o processo avaliativo mais claro e acessível.

O instrumento anterior era bastante pontual na avaliação, subdividindo-se em aspectos cognitivos e técnicos. O modelo proposto tornou-se mais discursivo e flexível, abrangendo várias dimensões do desenvolvimento cognitivo, atitudinal, técnico, emocional e político.

Os educadores detectaram a necessidade de refletir suas ações continuamente, com seus pares e também em ações de educação permanente com especialistas da área, pois à medida que se estuda, reflete-se acerca do que se está fazendo e aparecem interrogações por hora não respondidas, mas instigando-se a busca.

Nesse processo é possível reconhecer que o círculo de diálogo constituiu um espaço de encontro e descoberta do outro como sujeito - o docente, com aspirações, sentimentos e vivências que precisam ser desveladas a partir do diálogo no grupo, da participação nas discussões, da troca de conhecimentos e experiências. Isso promove o crescimento, pois possibilita descortinar a superação de limitações e dificuldades pessoais que condicionam o indivíduo a situações de submissão e acomodação diante de sua história de vida e de passividade ante os processos de exclusão em que atuam ${ }^{(19)}$.

\section{CONSIDERAÇÕES FINAIS}

Este estudo desenvolveu-se frente ao desejo de contribuição com os educadores de um curso profissionalizante em Enfermagem, mediante as avaliações que desenvolviam com os educandos numa proposta pedagógica de ensino por competência. Exigiu percorrer um caminho de muitas leituras e reflexões, possibilitando estar junto a eles, compartilhando experiências, discutindo expectativas, sentimentos e ideias coletivamente. Mas, acima de tudo, possibilitou compreender o significado da avaliação no ensino 
baseado em competências inspirado nos pressupostos de Perrenoud e Freire.

As discussões promovidas no espaço coletivo foram permeadas pelo diálogo entre os sujeitos envolvidos nas práticas pedagógicas/avaliativas, constituindo-se em significados e contribuições à avaliação da aprendizagem de forma a unir ação-reflexão-ação. Possibilitaram, ainda, mudanças e transformações das realidades vividas no processo ensino-aprendizagem.

Os educadores, a partir do desvelamento crítico, reconheceram que a avaliação precisa ser um processo dialógico, em que os sujeitos envolvidos se sintam ativos na construção, desenvolvimento e também nos resultados, porém não os supervalorizando e tampouco os percebendo como um fim. O processo avaliativo não só diagnostica a construção da aprendizagem como também orienta e reorienta formas de constituição do conhecimento.

Finalmente, cabe enfatizar que os educadores perceberam que a avaliação que era realizada por eles, ainda que dissessem ser por competência, era muito tradicional, ou seja, pontual, hierárquica e apenas cognitiva. Eles demonstraram consciência de que ainda precisam aprimorar o processo avaliativo dos alunos e que espaços dialógicos, de reflexão e possibilidade de

\section{REFERÊNCIAS}

1. Ministério da Educação. Lei de Diretrizes e Bases da Educação Nacional [Internet]. Brasilia:Ministério da Educação;1996 [cited 2010 out 14]. Available from:

http://www.planalto.gov.br/ccivil 03/leis/L9394.htm

2. Cruz AMP, Almeida MA. Competências na formação de Técnicos de Enfermagem para implementar a sistematização da assistência de Enfermagem. Rev Esc Enf. USP. [Internet]. 2010 [cited $2011 \mathrm{dez}$ 27];44(4):921-7. Available from

3. Paranhos VD, Mendes MMR. Currículo por competência e metodologia ativa: percepção de estudantes de enfermagem. Rev. Lat. Am. Enf. [Internet]. 2010 [cited 2012 jan 05]; 18(1):[7 telas]. Available from: http://www.scielo.br/pdf/rlae/v18n1/pt 17.pdf 4. Laluna MCMC, Ferraz CA. Os sentidos da prática avaliativa na formação de enfermeiros. Rev. Lat. Am. Enf. [Internet]. 2009 [cited 2012 jan 05]; 17(1):322-9. Available from:

http://www.scielo.br/pdf/rlae/v17n1/pt 04.pdf

5. Vasconcellos CMCB, Backes VMS, Martini JG. Avaliação no ensino de graduação em enfermagem na América Latina: uma revisão integrativa. Rev. Enfermería Global. 2011; 23:118-39.

6. Tronchin DMR, Gonçalves VIM, Leite MMJ,Melleiro MM. Instrumento de avaliação do aluno com base nas competências gerenciais do enfermeiro. Rev. Acta Paul Enferm 2008; 21(2):356-60. 7. Lima VV. Competence:different approaches and implications in the training of healthcare professionals.Interface - Comunic. Saúde. Educ. 2005; 9 (17): 369-79.

8. Perrenoud P. Avaliação da Excelência à Regulação das Aprendizagens - entre duas lógicas. Porto Alegre: Artes Médicas Sul; 2002. compartilhamento, são importantes para o despertar da consciência crítica.

Em suma, desencadear um processo de reflexão grupal, inspirado no Círculo de Cultura de Freire, no ambiente educacional demonstrou ser um espaço dialógico, onde os envolvidos podem ser ouvidos com respeito e desvelar a realidade, e transformá-la por meio da tomada de consciência crítica daquilo que precisa ser mudado.

Esse processo reflexivo grupal permitiu aos participantes do círculo - os educadores - compreender que o ato de avaliar significa aliar a competência técnica à afetividade e estimular os educandos a buscarem seus caminhos com a facilitação da aprendizagem por parte do educador. A avaliação pôde ser percebida como espaço de diálogo e de respeito, ressaltando-se a sua importância no suporte das práticas docentes em estudos aprofundados nas concepções do ensino por competência.

A partir destes resultados podemos inferir que o ensino por competência, na abordagem dialógica, é mais um desafio a ser conquistado. Apresenta-se como uma proposta consistente para a formação de profissionais da saúde mediante a problematização das necessidades sociais, tanto dos educandos e educadores quanto dos usuários.

9. Marques CMS. Egry EY. As competências profissionais em saúde e as políticas ministeriais. Rev. Esc. Enf. USP. [Internet]. 2011 [cited 2012 jan 11]; 45(1): 187-193. Available from:

http://www.scielo.br/pdf/reeusp/v45n1/26.pdf.

10. Brandão CR. O que é o método Paulo Freire? $25^{\text {a }}$ ed. São Paulo: Brasiliense; 1986.

11. Freire P. A pedagogia do oprimido. $45^{\mathrm{a}}$ ed. Rio de Janeiro: Paz e Terra; 2006.

12. Cruz ICF. Learning evaluation in education online - evidenced based practice. Rev. Online Brazilian Journal of Nursing. [Internet]. 2009; 8(2):148-52.

13. Silva KL, Sena RR. A educação de enfermagem: buscando a formação crítico - reflexiva e as competencias profissionais. Rev. Lat. Am. Enf. [Internet]. 2006 [cited 2012 jan 05]; 14(5):113-18.

Available from:

http://www.scielo.br/pdf/rlae/v14n5/pt_v14n5a18.pdf

14. Franco TB. Produção do cuidado e produção pedagógica: integração de cenários do sistema de saúde no Brasil. Rev. Interface. [Internet]. 2007 [cited 2012 jan 11]; 11(23): 427-38. Available from: http://www.scielo.br/pdf/icse/v11n23/a03v1123.pdf

15. Carraro TE, Prado ML, Silva DGV, Radünz V, Kempfer SS, Sebold, LF. Socialização como processo dinâmico de aprendizagem na enfermagem. Uma proposta na metodologia ativa. Rev Invest Educ Enferm. 2011; 29(2):249-54.

16. Gubert E, Prado ML. Desafios na prática pedagógica na educação profissional em enfermagem. Rev. Eletr. Enf. [Internet]. 2011[cited 2012 jan 11]; 13(2): 285-95 Available from: http://portais.ufg.br/deploy/projetos/fen_revista/v13/n2/pdf/v13n2 a15.pdf 
17. Moya J, Backes VMS, Prado ML, Sandin MP. La enfermería como grupo oprimido:las voces de las protagonistas. Texto contexto enferm. [Internet]. 2010 [cited 2012 jan 11]; 19(4):609-17. Available from: http://www.scielo.br/pdf/tce/v19n4/02.pdf

18. Mangueira SO, Fontes WD. O processo de enfermagem na matriz curricular de escolas formadoras de técnicos de enfermagem. Rev. Eletr. Enf. [Internet]. 2008 [cited 2012 jan 11]; 10(2):438-47.

Available from:

http://www.fen.ufg.br/revista/v10/n2/v10n2a15.htm

19. Monteiro EMLM, Vieira NFC. Educação em saúde a partir de círculos de cultura. Rev. Bras. Enf. [Internet]. 2010[cited 2012 jan 11];63(3):397-403. Available from:

http://www.scielo.br/pdf/reben/v63n3/a08v63n3.pdf

Artigo recebido em 17.12.2010.

Aprovado para publicação em 13.03.2012

Artigo publicado em 30.03.2012. 